\title{
PARTISIPASI WANITA PEKERJA SEKTOR INFORMAL DALAM KELUARGA BERENCANA DI KECAMATAN TEMON KABUPATEN KULON PROGO
}

\author{
Nina Damayanti* \\ Fakultas Ilmu Sosial, Universitas PGRI Palembang, Indonesia \\ Diterima Agustus 2017; Disetujui Oktober 2017; Dipublikasikan Desember 2017
}

\begin{abstract}
Abstrak
Hasil penelitian sebanyak 58\% wanita yang bekerja dalam sektor informal ikut serta dalam keluarga berencana, dan sebanyak $42 \%$ tidak mengikut keluarga berencana jumlah yang tidak ikut dalam keluarga berencana masih sangat banyak, namun saat dilakukan wawancara dengan beberapa responden mengatakan bahwa alasan mereka tidak ikut KB karena ada yang belum mempunyai anak dan ada juga yang sedang program hamil untuk menambah anak lagi, dan ada juga yang mengunakan KB secara alami. Terkait partisipasi wanita pekerja sektor informal dalam keluarga berencana dapat diketahui bahwa tingkat pendidikan tidak mempengaruhi partisipasi wanita pekerja sektor informal dalam keluarga berencana (menggunakan KB). Korelasi crostab partisipasi KB dengan pendidikan didapat angka probabilitas $0.10(0.10>0.05)$. Hubungan antar tingkat pendapatan dan partisipasi KB menghasilkan angkat 0.05 menunjukan sangat lemahnya korelasi. Korelasi tingkat pendapatan responden dengan partisipasi didapat angka probabilitas 0.94 (0.95 $>0.05$ ), artinya tidak ada hubungan yang signifikan dan saling mempengaruhi antara tingkat pendapatan dan partisipasi dalam KB.
\end{abstract}

Kata Kunci : Wanita Pekerja Sektor Informal, Keluarga Berencana

\begin{abstract}
Result shown 58\% of women working in the informal sector participated in family planning, and as many as $42 \%$ did not follow family planning unlimited amounts in family planning were still very much, but when interviewed with some respondents said that the reason they did not take family planning because there are not yet have children and there is also a pregnant program to add more children, and some are using KB naturally. In relation to the participation of women in informal sector workers in family planning, it can be seen that the level of education does not affect the participation of women in informal sector workers in family planning (using FP). The correlation of crostab of family planning participation with education was obtained by probability $0.10(0.10>0.05)$. The relationship between income level and FP participation resulted in a 0.05 lift indicating very weak correlation. Correlation of income level of respondents with participation obtained probability 0.94 (0.95> 0.05), meaning there is no significant relationship and influence between income level and participation in family planning
\end{abstract}

Keywords: Informal Women Working Group, Family Planning

How to Cite : Damayanti, N., (2017). Partisipasi Wanita Pekerja Sektor Informal Dalam Keluarga Berencana Di Kecamatan Temon Kabupaten Kulon Progo Daerah lstimewa Yogyakarta 5 (2): 17-24
${ }^{*}$ Corresponding author:
P-ISSN-2549-9165
E-mail: nina.damayati9ı@gmail.com
e-ISSN -2580-2011 


\section{PENDAHULUAN}

Kegiatan ekonomi di sektor informal semakin berkembang seiring dengan bertambahnya angka pengangguran, keberadaan sektor informal disatu sisi dibutuhkan masyarakat terutama di kalangan ekonomi menengah kebawah, tetapi di sisi lain kurang mendapatkan perhatian dan perlindungan dari pemerintah, padahal sektor ini identik dengan sektor usaha yang padat karya yang mampu menyerap banyak pengangguran dan sektor ini juga mampu memberikan pendapatan yang cukup tinggi untuk mengurangi tingkat kemiskinan

Kesulitan ekonomi dan tuntutan biaya kehidupan yang semakin tinggi, telah mendorong sebagian besar kaum wanita untuk ikut berperan dalam meningkatkan pendapatan keluarganya. Bagi kaum wanita yang telah berkeluarga umumnya mereka bekerja untuk menambah penghasilan suami demi mencukupi biaya kehidupan sehari-hari. Wanita saat ini tidak hanya berperan sebagai ibu rumah tangga, bahkan saat mereka bekerja, pendapatannya secara maksimal digunakan untuk memenuhi kebutuhan dalam keluarga, wanita yang tidak mempunyai pendidikan yang tinggi dan skill membuat para ibu rumah tangga berpikir kreatif untuk mencari uang tambah dengan menggunakan menggunakan tenaga dan tingkat upah yang rendah.

Peran sektor informal menjadi penting, karena kemampuan sektor informal dalam menyerap tenaga kerja dan tidak menuntut keterampilan yang tinggi. Bahkan sektor informal ini dapat dijadikan wadah dalam mengembangkan sumber daya manusia, dimana tenaga kerja yang tidak terlatih dapat meningkatkan keterampilan dengan masuk sektor informal terlebih dahulu sebelum masuk kesektor formal.

Sektor informal memiliki karateristik seperti jumlah unit usaha yang banyak dalam skala kecil; kepemilikan oleh individu atau keluarga, teknologi yang sederhana dan padat tenaga kerja, tingkat pendidikan dan keterampilan yang rendah, produktivitas tenaga kerja yang rendah dan tingkat upah yang relative lebih rendah bila dibandingkan sektor informal. Motivasi kerja para pekerja sektor informal adalah memperoleh pendapatan yang cukup untuk sekedar bertahan hidup (survival).
Sektor informal banyak menyerap tenaga kerja yang mempunyai keterampilan yang rendah karena memang tingkat pendidikanya juga rendah sehingga tidak mempunyai skill dan keterampilan yang diperoleh berdasarkan pengalaman, modal yang sedikit, dan teknologi yang digunakan sederhana, sehingga pendapatan yang dihasilkan juga rendah. Dewasa ini tidak hanya laki-laki banyak yang bekerja disektor informal, namun juga wanita sebagai upaya untuk membantuh perekonomian keluarga. Karena pekerjaan disektor informal tidak menuntut waktu yang telah ditentukan terorganisir oleh atasan, namun waktunya sesuai dengan permintaan pasar dan keadaan wanita itu sendiri jadi tidak ada tekanan dalam waktu bekerja, wanita bisa mulai bekerja setelah selesai mengerjakan pekerjaan rumah. Sehingga selain mendapatkan uang tambah dari pekerjaanya disektor informal seperti dagang, jasa, dan pertanian juga pekerjaan rumah tangga dapat dikerjakan sendiri.

Suatu program dikatakan berhasil apabila masyarakat ikut serta berpartisipasi dalam kegiatan progam tersebut, dan sebalikya program keluarga berencana dikatakan gagal jika tidak ada tanggapan dan partisipasi dari masyrakat. KB merupakan program yang bertujuan untuk menjarangkan kehamilan, membatasi jumlah anak, mengatur jarak kelahiran antar anak, dll. Dengan melihat karakteristik pekerja sektor informal ialah berpendidikan rendah, dan pendapatan juga rendah, maka disini peneliti ingin melihat apakah pendidikan wanita pekerja sektor informal dan pendapatan total keluarga wanita pekerja sektor informal mempengaruhi tingkat partisipasi dalam keluarga berencana.

Tujuan dalam Penelitian ini adalah untuk mengetahui apakah wanita yang bekerja dalam bidang sektor informal berpartisipasi dalam program keluarga berencana. Mengetahui apakah jenjang pendidikan dan pendapatam pada wanita pekerja sektor informal mempengaruhi partisipasi program keluarga berencana.

Partisipasi diartikan keterlibatan seseorang secara sadar kedalam interaksi sosial dalam situasi tertentu (Wazir dan Achmad dalam Arsanti 2012). Partisipasi adalah keikut sertaan masyarakat dalam 
proses pengidentifikasian masalah dan potensi yang ada di masyarakat, pemilihan dan pengambilan keputusan tentang alternatif solusi untuk menangani masalah, pelaksanaan upaya mengatasi masalah, dan keterlibatan masyarakat dalam proses pengevaluasian perubahan yang terjadi ( Isbandi, 2007)

Menurut Muhajir (1980) juga melihat pasrtisipasi dalam empat kegiatan yakni:

a. Keterlibatan orang dalam proses pengambilan keputusan

b. Keterlibatan orang di dalam pelaksanaan program dan pengambilan keputusan

c. Keterlibatan orang didalam menikmati hasil dari kegiatan

d. Keterlibatan didalam evaluasi suatu progam yang sudah terlaksana

Jadi dapat disimpulkan bahwa partisipasi merupakan keikutsertaan individu atau masyaraakat dalam suatu progaram atau kegiatan secara aktif sukarela dengan alasaalasan tertentu untuk memcapai tujuan tertertentu.

Partisipasi wanita pekerja sektor informal dalam program KB merupakan bagian terpenting untuk mewujudkan masyarakat yang sejaterah akan terbentuk keluarga kecil yang bahagia dan berkualitas, walaupun sekarang tidak hanya wanita yang menggunkan KB tertapi juga pria, namun disini peneliti akan melihat partisipasi KB pada wanita yang bekerja disektor informal dan apabila ada suami yang ikut program KB karena alasan istri tidak cocok atau tidak bisa menggunakan KB karena mengganguu kesehatan istri maka hal tersebut termasuk dalam objek peneliti.

\section{Sektor Informal}

Kantor mentri Negara Urusan Peranan pemerintah, Unicef, dan BPS menjelaskan bahwa kegiantan informal adalah berusaha atau bekerja sendiri atas resiko sendiri, berusaha dengan resiko sendiri dengan dibantuh oleh buruh tidak tetap, dan bekerja yang tidak dibayar seperti mereka yang membantuh seseorang memperoleh penghasilan atau keuntungan, namun tidak mendapat upah atau gaji baik berupa uang atau barang. Kantor Mentri Negara Urusan peranan wanita, Unicef, dan BPS juga menyebutkan ciri-ciri pekerja sektor informal antara lain:

a. Kegiatan tidak terorganisir dengan baik, karena timbulnya tidak mempergunkan fasilitas kelembagaan formal yang ada.

b. Tidak mempunyai izin usaha

c. Lokasi dan jam kerja tidak teratur

d. Tidak terjangkau langsung kebijakan pemerintah untuk membantuh golongan ekonomi lemah

e. Unit usaha mudah beralih antara subsektor

f. Berteknologi sederhana

g. Skala operasinya kecil

h. Tidak memerlukan pendudukan formal, hanya berdasarkan pengalaman

i. Bekerja sendiri tau hanya dibantuh pekerja keluarga tanpa dibayar

j. Berusaha dengan modal sendiri atau dari lembaga keuangan tidak resmi

k. Produknya hanya dikonsumsi masyarakat berpenghasilan rendah dan sebagian kecil berpenghasilan menengah.

Pekerjan sektor informal dibedakan antara informal pertanian dan non-pertanian. Keduanya mempunyai sifat yang berbeda, dan membawa masalah yang berbeda pula. Informal pertanian bersifat tradisional, sudah ada dalam ekonomi sejak semula, memiliki peranan khusus, memiliki problem khusus dan memerlukan penangan yang spesifik, sedangkan sektor non pertanian lebih merupakan produk dari pembangunan ekonomi yang tidak dapat menyerap pertambahan tenaga kerja yang ada.

\section{Keluarga Berencana}

Menurut WHO (1970) yang dikutip oleh Amini (2011), arti keluarga berencana itu sendiri adalah tindakan yang membantuh individu atau pasangan suami istri untuk mendapatkan obyek tertentu, yaitu (1) menghindari kelahiran yang tidak di inginkan, (2) mendapatkan kelahiran yang memang diingikan, (3) mengatur interval diantara kehamilan, (4) menentukan jumlah anak dalam keluarga secara bertanggung jawab.

Partisipasi wanita pekerja sektor informal dalam KB di Desa Sindutan Kecamatan Temon diukur melalui kesertaan mereka ber KB (pemakaian alat kontrasepsi) yang mana akan dilihat apakah pendidikan dan pendapatan wanita pekerjaan sektor informal akan mempengaruhi keikut sertaan mereka dala $\mathrm{m}$ program KB. Karena secara teroritis semakin besar pendapat keluarga 
pekerja sektor informal maka akan semakin tinggi tingkat partisipasi karena mereka mampuh untuk membayar pelayanan dan alat kontrasepsi yang akan digunakan. Begitu juga dengan tingkat pendidikan semakin tinggi tingkat pendidikan wanita pekerja sektor informal maka tingkat partisipasinya dalam program KB akan semakin tinggi, karena wanita yang mempunyai tingkat pendidika yang tinggi akan mudah mengakses informasi tentang KB baik yang berasal dari media elektronik ( TV, Radio, Internet, dll) maupun media cetak ( Koran, majalah, tabloid. Baliho atau sepanduk).

\section{METODE PENELITIAN}

Metode penelitian ini menggunakan metode Survei untuk sampling dan menggunakan metode deskriptif kuantitatif untuk analisisnya yang lebih menekan pada produk. Teknik pengumpulan data menggunakan observasi, wawancara, dan dokumentasi. Teknik analisis data tabel frekuensi, crosstab.

Dalam penelitian ini yang menjadi populasi adalah masyarakat Desa Sindutan Kecamatan Temon yang terdiri dari 7 duku

Tabel 1. Interprestasi Hasil Uji Korelasi

\begin{tabular}{|c|c|c|c|}
\hline No & Parameter & Nilai & Interprestasi \\
\hline & \multirow[t]{5}{*}{ Kekuatan Korelasi (r) } & $0,00-0.199$ & Sangat Lemah \\
\hline & & $0.20-0.399$ & Lemah \\
\hline & & $0.40-0.599$ & Sedang \\
\hline & & $0.60-0.799$ & Kuat \\
\hline & & $0.80-1,00$ & Sangat Kuat \\
\hline \multirow[t]{2}{*}{2.} & \multirow[t]{2}{*}{$\begin{array}{l}\text { Nilai p (dalam } \text { SPSS } \\
\text { ditunjukan dengan nilai } \\
\text { signifikan) }\end{array}$} & $\mathrm{P}<0.05$ & $\begin{array}{l}\mathrm{H}_{\mathrm{o}} \text { ditolak, terdapat korelasi yang } \\
\text { bermakna anatara dua variabel } \\
\text { yang diuji }\end{array}$ \\
\hline & & & $\begin{array}{l}\mathrm{H}_{\mathrm{o}} \text { diterima, tidak terdapat } \\
\text { korelasi yang bermakna antara } \\
\text { dua variabel yang diuji }\end{array}$ \\
\hline \multirow[t]{2}{*}{3.} & \multirow[t]{2}{*}{ Arah korelasi } & Positif $(+)$ & $\begin{array}{l}\text { Searah, semakin besar nilai satu } \\
\text { variabel semakin besar pula nilai } \\
\text { variabel yang lain }\end{array}$ \\
\hline & & Negatid (- ) & $\begin{array}{l}\text { Berlawanan arah, semakin besar } \\
\text { nilai satu variabel, semakin kecil } \\
\text { nilai variabel lainnya }\end{array}$ \\
\hline
\end{tabular}

Sumber : Aminah, 2011

\section{HASIL DAN PEMBAHASAN}

Partisipasi Wanita Pekerja Informal dalam Keluarga Berencana

Wanita yang bekerja dalam sektor informal merupakan bagian dari yaitu Bayema, Dukuh, Sindutan A, Sindutan B Lempukan, Glaeng, Paningan, dengan jumlah populasi sekitar $537 \quad$ KK (Rumah Tangga).karena jumlah populasi terlalu besar maka populasi tersebut akan di sampel, penentuan ukuran sampel menggunakan rumus solving (Selvilla:2007) dari hasil perhitungan maka dapat dibulatkan menjadi 84 responden. Kemudian dari 84 responden dipilih lagi menjadi 43 responden yang memenuhi criteria sebagai wanita yang bekerja disektor informal.

Teknik analisis data tabel frekuensi digunakan untuk penyederhanaan data yang cukup banyak. Sedangkan crosstab untuk mengetahui seberapa besar hubungan antara kedua variabel berkenaan dengan besar angka, angka korelasi berkisar 0 atau tidak ada korelasi sama sekali dan 1 (korelasi sempurna). Maka, dapat dikatakan angka korelasi diatas 0.5 menunjukan korelasi yang cukup kuat sedangkan dibawah 0.5 korelasi lemah. Interprestasi hasil uji korelasi didasarkan pada nilai $\mathrm{p}$, kekuatan korelasi serta arah korelasinya, dapat dilihat pada tabel 3.1. beikut: 
keluarga berencana. Hasil yang didapat dilapangan mengenai jumlah wanita yang ikut dalam program keluarga berencana dapat dilihat pada tabel beriku:

Tabel 2

Partisipasi Wanita Pekerja Informal dalam Kelaurga Berencana

\begin{tabular}{|c|c|c|c|c|}
\hline \multirow{2}{*}{$\begin{array}{l}\text { Pekerja } \\
\text { Informal }\end{array}$} & \multicolumn{4}{|c|}{$\begin{array}{lll}\text { Partisipasi } & \text { dalam } & \text { Keluarga } \\
\text { Berencana } & & \\
\end{array}$} \\
\hline & Ya & $\begin{array}{l}\text { Persen } \\
\text { tasi }\end{array}$ & & $\begin{array}{l}\text { Persent } \\
\text { asi }\end{array}$ \\
\hline Jumlah & 25 & $58 \%$ & 18 & $42 \%$ \\
\hline
\end{tabular}

Tabel diatas dapat dilihat bahwa sebanyak $58 \%$ wanita yang bekerja dalam sektor informal ikut serta dalam keluarga berencana, dan sebanyak $42 \%$ tidak mengikut keluarga berencana jumlah tersebut masih sangat banyak, namun saat dilakukan wawancara dengan beberapa responden mengatakan bahwa alasan mereka tidak ikut KB karena ada yang belum mempunyai anak dan ada juga yang sedang program hamil untuk menambah anak lagi, dan ada juga yang mengunakan KB secara alami.

Hubungan Tingkat Pendidikan Wanita Pekerja Informal Terhadap Partisipasi dalam KB

Pendidikan merupakan salah satu faktor yang diharapkan mendukung adanya program keluarga berencana ( KB). Desa Sindutan tercatat 43 wanita yang bekerja disektro informal yang menjadi respondent penelitian. Tingkat pendidikan terbagi menjadi 7 golongan dan jumlah respondent yang tamat pendidikan sesuai dengan jenjangnya, dari 43 responden terdapat tidak sekolah $5 \%$, tamat SD $16 \%$, SMP $28 \%$, SMA $46 \%$, perguruan tinggi D3 dan stratra satu sebanyak $5 \%$.

Tabel 3. Hubungan Tingkat Pendidikan Terhadap Partisipasi dalam KB

\begin{tabular}{|c|c|c|c|c|c|c|}
\hline \multirow[b]{2}{*}{ Pendidikan } & \multicolumn{4}{|c|}{ Partisipasi dalam KB } & \multirow{2}{*}{$\begin{array}{l}\text { Jumlah } \\
\text { Responden }\end{array}$} & \\
\hline & idak & $\begin{aligned} & \text { Perse } \\
& \text { ntase }(\%)\end{aligned}$ & a & $\begin{array}{r}\text { Perse } \\
\text { ntase (\%) }\end{array}$ & & \\
\hline $\begin{array}{l}\text { Tidak } \\
\text { Sekolah }\end{array}$ & 2 & 11 & & 0 & 2 & \\
\hline SD & 4 & 22 & & 12 & 7 & 6 \\
\hline SMP & 4 & 22 & & 32 & 12 & 8 \\
\hline SMA & 6 & 34 & 4 & 56 & 20 & 6 \\
\hline $\begin{array}{l}\text { Perguruan } \\
\text { Tinggi }\end{array}$ & 2 & 11 & & 0 & 2 & \\
\hline Jumlah & 8 & 100 & 5 & 100 & 43 & 00 \\
\hline
\end{tabular}

Sumber: Data Primer, 2014

Tingkat partisipasi diukur dari dari apakah perempuan yang berpendidikan yang tinggi menggunakan $\mathrm{KB}$ atau tidak, perempuan yang tergolong pendidikan tinggi yaitu yang tama D3/ akademi samapi tamat S3 namun disini jumlah pempuan yang berekrja disektor infomal yang mempunyai pendidikan tergolong tinggi hanya $5 \%$ tamat D3 dan Sl, karena memang pekerja sektof informal tidak membutuhkan pendidikan yang tinggi dan mempunyai skill khusus. dan kedua responden yang bekerja sebagai pedagang tesebut tingkat pendidikan tergolong tinggi tamat D3/ Akademi tidak mengikut program KB.
Untuk tingkat pendidikan yang rendah tidak sekolah sebanyak 5\% dan tamat SD terdapat $16 \%$ dan respondent tersebut ada yang mengikut program KB dan ada juga yang tidak mengikut program KB. Begitu juga dengan tingkat pendidikan sedang yaitu tamat SMP sebanyak $28 \%$ dan SMA terdapat $46 \%$ dilihat dari tingkat pendidikan, tingkat pendidikan SMA mempunyai persentasi paling banyak wanita yang tidak ikut serta dalam keluarga berencana, namun jumlah yang paling banyak juga diikuti oleh persentase wanita yang mengikuti program keluarga berencana. 
Nina Damayanti, (2017). Studi Partisipasi Wanita Pekerja Sektor Informal Dalam Keluarga Berencana

Tabel 4. Symmetric Measures

\begin{tabular}{|l|l|l|}
\hline & Value & $\begin{array}{l}\text { Approx. } \\
\text { Sig. }\end{array}$ \\
\hline $\begin{array}{l}\text { Nominal Conting } \\
\text { by } \begin{array}{l}\text { ency } \\
\text { Nominal }\end{array}\end{array}$ & $\begin{array}{l}\text { Coeffici } \\
\text { ent }\end{array}$ & \\
N of Valid Cases & 43 & \\
\hline
\end{tabular}

Hubungan yang signifikan antara partisipasi dengan tingkat pendidikan ditunjukan dari hasil analisi korelasi crosstab antara tingkat pendidikan dengan partisipasi KB ( menggunakan KB) menghasilkan angkat 0.391 menunjukan hubungan yang lemah. Korelasi crostab partisipasi KB dengan pendidikan didapat angka probabilitas 0.10 ( $0.10>0.05)$ maka tolak $\mathrm{Ha}$ dan terima $\mathrm{H}_{0}$ artinya tidak ada hubungan antara tingkata pendidikan dengan partisipasi dalam program keluaraga berencana (KB).

Tidak adanya hubungan yang signifikan antara tingkat pendidikan dan partisipasi $\mathrm{KB}$ di desa Sindutan karena program keluarga berencana di Desa sindutan sudah baik, dinas kesehatan setempat sudah memberikan pelayanan KB dengan maksimal ini terbukti dengan program jangka panjang yang diberikan secara gratis. Seperti pemasangan IUD dan susuk KB secara gratis. Sehingga walaupun pendidikan wanita yang bekerja disektor informal tidak tinggi namun kesadaran akan menggunakan KB sudah baik.

\section{Hubungan Tingkat Pendapatan Keluarga Wanita Pekerja Sektor Informal Terhadap Partisipasi dalam KB}

Pendapatan merupakan merupakan salah satu faktor yang diharapkan mendukung adanya program keluarga berencana (KB). dari 43 responden wanita pekerja sektor informal maka dapat dikelompokan 3 (tiga) kategorei pendapatan yaitu pendapatan rendah, sedang, dan tinggi. Pendapatan rendah yang berpenghasilan < 2.033.333, pendapatan sedang 2.033.334 - 4.066.666, pendapatan tinggi 4.066.667 - 6.099.999. untuk melihat apakah ada hubungan yang signifikan antara tingkat pendapatan keluarga wanita pekerja informal terhadap partisifasi dalam KB dapat dilihat pada tabel 5 dibawah ini:

anita Pekerja Sektor Informal

\begin{tabular}{|l|l|l|l|l|l|l|c|}
\hline \multirow{2}{*}{ No } & \multirow{2}{*}{ Tingkat Pendapatan } & \multicolumn{4}{|c|}{ Partisipasi dalam KB } & \multirow{2}{*}{ Jumlah } & \multirow{2}{*}{ Persentase } \\
\cline { 3 - 7 } & & Tidak & $\%$ & ya & $\%$ & & \\
\hline 1 & Rendah & 13 & 2 & 18 & 72 & 31 & 72 \\
\hline 2 & Sedang & 4 & 22 & 5 & 20 & 9 & 21 \\
\hline 3 & Tinggi & 1 & 6 & 2 & 8 & 3 & 7 \\
\hline \multicolumn{2}{|l|}{ Jumlah } & 18 & 100 & 25 & 100 & 43 & 100 \\
\hline
\end{tabular}

Sumber: Data primer, 2014

Tabel 6. Symmetric Measures

\begin{tabular}{|c|c|c|}
\hline & Value & Sig. \\
\hline $\begin{array}{c}\text { Nominal by Contingency } \\
\text { Nominal Coefficient } \\
\mathrm{N} \text { of Valid Cases }\end{array}$ & .052 & .944 \\
\hline
\end{tabular}

Dari tabel 5 tersebut maka dapat dilihat responden yang mempunyai pendapatan rendah terdapat $72 \%$ yang tidak mengikuti program KB dan jumlah yang sama juga yang mengikuti program KB. Untuk pendapatan golongan menegah sebanyak 22\% yang tidak ikut program KB dan $20 \%$ yang ikut program $\mathrm{KB}$, sedangkan untuk pendapatan tinggi lebih banyak yang ikut program KB yaitu $8 \%$ dan $6 \%$ yang tidak ikut program KB.

Hubungan tingkat pendapatan dan partisipasi KB menghasilkan angkat 0.05 menunjukan sangat lemahnya korelasi. Korelasi tingkat pendapatan respondepn dengan partisipasi didapat angka probabilitas 0.94 (0.95 >0.05) maka $\mathrm{Ha}$ ditolak dan $\mathrm{H}_{\mathrm{a}}$ 
diterima, artinya tidak ada hubungan yang signifikan dan saling mempengaruhi antara tingkat pendapatan dan partisipasi dalam KB.

Tingkat pendapatan tidak mempunyai hubungan yang signifikan dikarenakan program KB di Desa Sindutan tergolong murah dan bahkan dinas kesehatan setempat sering memberikan palayanan dan alat kontrasepsi jangka panjang yang diberikan secara gratis, sehingga tingkat pendapatan tidak mempengaruhi tingkat penggunaan $\mathrm{KB}$ di Desa Sindutan. Ada beberapa alat KB yang dipakai responden harus membayar seperti jenis KB suntuk dan pil yang mana sifatnya jangka pendek yang biasa dilakukan setiap bulan atau tiga bulan sekali untuk membeli dan mendapatkan pelayanan dan alat kontrasepsi tersebut, dan sebagaian responden mengatakan alat kontrasepsi tersebut didapat dengan harga yang murah. maka responden harus membayar berikut ini persepsi harga alat kontrasepsi yang dipakai oleh responden yang harus membayar.

Tabel 7. Tingkat Pendapatan Keluarga Wanita Pekerja Sektor Informal

\begin{tabular}{|l|l|l|l|l|l|l|l|}
\hline \multirow{2}{*}{ No } & \multirow{2}{*}{ Biaya KB } & \multicolumn{2}{|l|}{ Partisipasi dalam KB } & \multirow{2}{*}{ Jumlah } & \multirow{2}{*}{ Persentase } \\
\cline { 3 - 8 } & & Tidak & $\%$ & Ya & $\%$ & & 72 \\
\hline $\mathbf{1}$ & Murah & 11 & 61 & 12 & 48 & 31 & 72 \\
\hline $\mathbf{2}$ & Sedang & 2 & 11 & 7 & 28 & 9 & 21 \\
\hline 3 & Mahal & 2 & 11 & 4 & 16 & 3 & 7 \\
\hline & Tidak Tahu & 3 & 17 & 2 & 8 & & 100 \\
\hline \multicolumn{2}{l}{ Jumlah } & 18 & 100 & 25 & 100 & 43 & 100 \\
\hline
\end{tabular}

Sumber: Data primer, 2014

Dari Tabel 7 sebanyak 61\% wanita yang tidak memakai KB mengatakan biaya KB murah, dan $48 \%$ yang ikut KB mengatakan biaya KB murah, sebagian besar responden mengatakan bahwa biaya KB murah, sehingga disini dapat dibuktikan bahwa biaya program KB tidak mahal untuk sebagian besar penduduk yang ada di Desa Sindutan dan mereka tidak menyiapkan biaya khusus untuk program KB. Untuk responden yang mengatakan biaya KB sedang terdapat 2 responden yang tidak mengikuti KB dan 7 responden yang ikut KB.Dan Untuk pendapat masyarakat yang mengatakan biaya KB mahal terdapat 2 yang tidak ikut KB dan 4 yang ikut KB. Dan terdapat lima responden yang mengatakan tidak tau apakah biaya untuk program KB murah, sedang, mahal. Berikut Tabel dibawah ini menjelaskan jenis KB yang dipakai responden:

Tabel 8. Jenis KB Yang Dipakai

\begin{tabular}{|l|l|l|}
\hline No & Jenis KB & Jumlah \\
\hline 1 & Spiral/IUD & 6 \\
\hline 2 & Pil & 11 \\
\hline 3 & Suntik & 8 \\
\hline 4 & Steril & 1 \\
\hline 5 & Kondom & 1 \\
\hline 6 & Tidak mengikuti KB & 16 \\
\hline \multicolumn{2}{|l|}{ Jumlah } & 43 \\
\hline
\end{tabular}

Sumber: Data primer, 2014

Dari Tabel dapat dijelaskan bahwa sebagian besar jenis KB yang dipakai ialah jenis KB pil, kemudian suntik. Dari 43 responden terdapat 16 responden yang tidak menggunakan $K B$, mereka yang tidak memakai KB ada yang memang belum mempunyai anak, ingin menambah anak lagi, dan juga menunda kehamilan dengan metode tradisional seperti perhitungan kalender, poso, dll.

\section{Simpulan}

Hasil penelitian sebanyak $58 \%$ wanita yang bekerja dalam sektor informal ikut serta dalam keluarga berencana, dan sebanyak $42 \%$ tidak mengikut keluarga berencana jumlah tersebut masih sangat banyak, namun saat dilakukan wawancara dengan beberapa responden mengatakan bahwa alasan mereka 
Nina Damayanti, (2017). Studi Partisipasi Wanita Pekerja Sektor Informal Dalam Keluarga Berencana

tidak ikut KB karena ada yang belum mempunyai anak dan ada juga yang sedang program hamil untuk menambah anak lagi, dan ada juga yang mengunakan KB secara alami.

Berdasarkan penelitian dapat diketahui
bahwa tingkat pendidikan tidak mempengaruhi partisipasi wanita pekerja sektor informal dalam keluarga berencana (menggunakan KB). Korelasi crostab partisipasi KB dengan pendidikan didapat angka probabilitas $0.10(0.10>0.05)$ hubungan yang lemah. Tidak adanya hubungan yang signifikan antara tingkat pendidikan dan partisipasi KB di desa Sindutan karena program keluarga berencana di Desa sindutan sudah baik, dinas kesehatan setempat sudah memberikan pelayanan KB dengan maksimal ini terbukti dengan program jangka panjang yang diberikan secara gratis.

Tingkat pendapatan dengan partisipasi dalam KB ditunjukan dari hasil analisis korelasi crostab didapat angkat 0.05 menunjukan korelasi yang sangat lemah. Korelasi tingkata pendapatan respondepn dengan partisipasi didapat angka probabilitas 0.94 (0.95 >0.05) maka Ha ditolak dan $\mathrm{H}_{\mathrm{a}}$ diterima, artinya tidak ada hubungan yang signifikan dan tidak saling mempengaruhi antara tingkat pendapatan dan partisipasi dalam KB. Tingkat pendapatan tidak mempunyai hubungan yang signifikan dikarenakan program KB di Desa Sindutan tergolong murah dan bahkan dinas kesehatan setempat sering memberikan palayanan dan alat kontrasepsi jangka panjang yang diberikan secara gratis, sehingga tingkat pendapatan tidak mempengaruhi tingkat penggunaan KB di Desa Sindutan. Ada beberapa alat KB yang dipakai responden harus membayar seperti jenis KB suntuk dan pil yang mana sifatnya jangka pendek yang biasa dilakukan setiap bulan atau tiga bulan sekali untuk membeli dan mendapatkan pelayanan dan alat kontrasepsi tersebut, dan sebagaian responden mengatakan alat kontrasepsi tersebut didapat dengan harga yang murah.

\section{DAFTAR PUSTAKA}

Aminah, Siti. 2011. Research Methodologi. Yogyakarta. Muhamadiyah University

Amini, Nyigit W. 2011. Implementasi Kebijakan Program KB Priastudi khasus Tingginya Pencapaian MOP di Kabupaten Situbondo Provinsi Jawa Timur. Yogyakarta:Universitas Gadjah Mada

Arsanti. Vidyana. 2012. Partisipasi Masyarakat Dalam Pengembangan Desa Wisata Dusun Sambai Desa Pakembinangun Kecamatan Pakem Kabupaten Sleman. Yogyakata. Tesis tidak diterbitkan. Universias Gadjah Mada

Muhajir, Noeng. 1980. Pendidikan dan Pembangunan Desa dan Administrasi Pemerintah Desa, Jakarta: Yayasan Karya Darma

Isbandi, Ruminto Adi. 2007. Perencanaan Partisipasi Berbasis Asas Komunikasi. dari http///.lsbandi.blog. diakses tanggal 29 juni 2014

Sevilla, Consuelo G. et. al (2007). Research Methods. Rex Printing Company. Quezon City. 